\title{
Engineering and environmental benefits of using construction wastes in ground improvement works
}

\author{
Cornelia-Florentina Dobrescu ${ }^{1, *}$,Elena-Andreea Calarasu ${ }^{2}$ \\ ${ }^{1}$ National Institute for Research and Development in Construction, Urban Planning and Sustainable \\ Spatial Development, Romania \\ ${ }^{2}$ Ministry of Regional Development and Public Administration, Romania
}

\begin{abstract}
One of the key emerging trends to protect the environment is to reuse wastes generated from construction and demolition sites for various engineering purposes. Many studies are being developed for setting up and optimize the potential of recycled construction wastes. The aim of the paper is to estimate the degree of improvement for resistance parameters of soil mixed with $5 \%$ and $10 \%$ of concrete and brick and water-based polymeric suspension used as stabilizer agent, as well as drywall waste mixed with 5\% eco-binder with puzzolanic character. Multiple options of mixtures, predominantly composed by clay soils with swelling potential, have been investigated in laboratory conditions in terms of compression strength at 7, 14 and 28 days curing time and deformability. In order to emphasize distinct benefits of tested mixtures, a comparative analysis of the parametric values has been achieved. The experimental results revealed the suitability of using construction wastes to be assimilated with natural or conventional materials, which leads to significant improvements rates of geotechnical parameters. A large-scale implementation of this type of practice can substantially contribute to the achievement of sustainable development targets by reusing construction waste according to the specific objectives of engineering works in terms of structure safety.
\end{abstract}

\section{Introduction}

According to recent statistics on development of waste management, building materials account approximately $25 \%-30 \%$ of all waste generated in the EU. This waste category, with huge negative impact on the environment, comes from different activities such as the construction of buildings and civil infrastructure, total or partial demolition of buildings and civil infrastructure, road planning and maintenance and consists of various materials, such as concrete, bricks, gypsum, wood, glass, metals, plastic, excavated soil, etc.

Considering the costs rising of the building materials and high demand on the market industry, as well as insufficient storages of raw materials and high energy prices, the use of

\footnotetext{
*Corresponding author: corneliadobrescu@yahoo.com
} 
alternative products in construction works has become a common approach for sustainable use of natural resources [1].

The Directive 2008/98/EC on waste includes specific provisions for the Member States to take the necessary measures designed to be achieved by 2020 , including a minimum of $70 \%$ shall be prepared for re-use, recycling and other recovery of construction and demolition waste (CDW). EU statistics indicates an annual CDW generation of 970 Mton in the EU-27, with an average recovery rate of $47 \%$. Although there is a high potential for recycling and re-use of CDW in roads, drainage and other construction projects $[2,3]$, it should be mentioned that several barriers were identified, such as lack of standardisation, awareness and resources, and therefore the process of re-use and recycling is considered to be slow-acting.

In this respect in order to achieve the targets set by the legislative framework, intensive efforts of the society as an easy starting point to introduce gradually the sustainability into the building sector have been made in the last decade.

Following the trend line of increasing focus on waste management $[4,5]$, the concerns of academic and research media, private sector involved in the manufacture of building products, building design and quality control have resulted in developing or improving various materials and technical solutions focused on the reuse of CDW to line up to the achievement of sustainable development targets. As a result of these approaches, numerous studies have been carried out for setting and optimizing the potential of CDW as substitutes for natural or conventional materials $[6,7]$ in order to ensure the safety and durability of engineering works beside the reduction of the environmental impact.

As a general view, the re-use of CDW is mainly focused on the manufacture of new building materials as aggregate in concrete, in admixtures with Portland cement. Subsequently, the potential of CDW for the stabilization of road layers has been remarked in several pilot studies and research projects [8-10]. More specifically, a considerable number of thematic studies have been dedicated for assessing the potential of CDW on the treatment of unstable soils for improving their mechanical characteristics [11, 12].

The present paper deals with the assessment of resistance parameters of various soil specimens mixed with $\mathrm{CDW}$ and additional eco-material in order to quantify the potential of applied procedure as a feasible technical solution and conforming also to the engineering and environmental criteria.

\section{Materials of admixtures and method for soil improvement}

To investigate the engineering benefits of using construction wastes as alternative materials with binder properties for assessing the degree of improvement for resistance parameters of the admixtures, small-scale treatment and experimental testing have been carried out.

Taking into consideration the fact that concrete and brick are common building materials, as well as the significant amount of waste generated worldwide, it was considered appropriate to integrate these waste materials into laboratory experiments. Moreover, in order to support the environmental requirements, water-based polymeric suspension and powder binder, generally used as stabilizer agent in engineering works, with confirmed results in road stabilization and manufacture of building materials such as bricks and blocks, was selected for the preparation of admixtures.

The reference test soil consisted in clay samples, with expansive character [13]. The construction wastes used for experimental testing were crushed and sorted with particle sizes of bricks between 0.05 and $0.3 \mathrm{~mm}$, respectively from 0.05 to $0.5 \mathrm{~mm}$ for concrete materials and $0.025-0.063 \mathrm{~mm}$ for drywall.

During the study, it was identified that the variables to be considered were the time, humidity, and temperature of curing, as well as the stabilizer agent. Therefore, a specific 
matrix was set by combining the reference soil with different percentages of waste and binders $(5 \%$ and $10 \%$ of concrete and brick and water-based polymeric suspension used as stabilizer agent, as well as drywall waste with $5 \%$ eco-binder with puzzolanic character), temperature and curing time (7,14 and 28 days at normal temperature and humidity).

The laboratory testing consists in assessing the behaviour of soil-waste admixtures under mechanical loading by performing uniaxial compression strength (UCS) and oedometric tests. Previous to the admixtures preparation, an initial determination of soil nature and characteristics, such as plasticity index, colloidal clay content, free swell and swelling pressure have been conducted for the reference soil type. According to the specific Romanian Norm, the soil was classified in the expansive category with high activity.

The test method was carried out by soil loading with a rate of strain of $0.05 \mathrm{~mm} / \mathrm{min}$ as typically used value for soft soils. Furthermore, the clayey material was dried and crushed to obtain particle sizes smaller than $2 \mathrm{~mm}$. In order to simulate excessive moisture conditions as it happens with expansive clays, the material was brought to a high value of water content of about 25 up to $30 \%$.

In order to quantify the effect of different waste addition on the variability of strength characteristics of mixture-based expansive soils, uniaxial compression strength tests (UCS) were carried out on molded cylindrical specimens, with diameter of approximately $50 \mathrm{~mm}$ and height of $100 \mathrm{~mm}$, cured at ambient temperature of $19-22^{\circ} \mathrm{C}$. Once curing was complete at 7, 14 and 28 days, UCS tests were performed immediately. Two sets of mixtures were prepared as a comparison. Three specimens from the first set of mixture with concrete and brick waste and water-based polymeric suspension were tested and the final result is the average of determined values, as represented in Fig. 1.

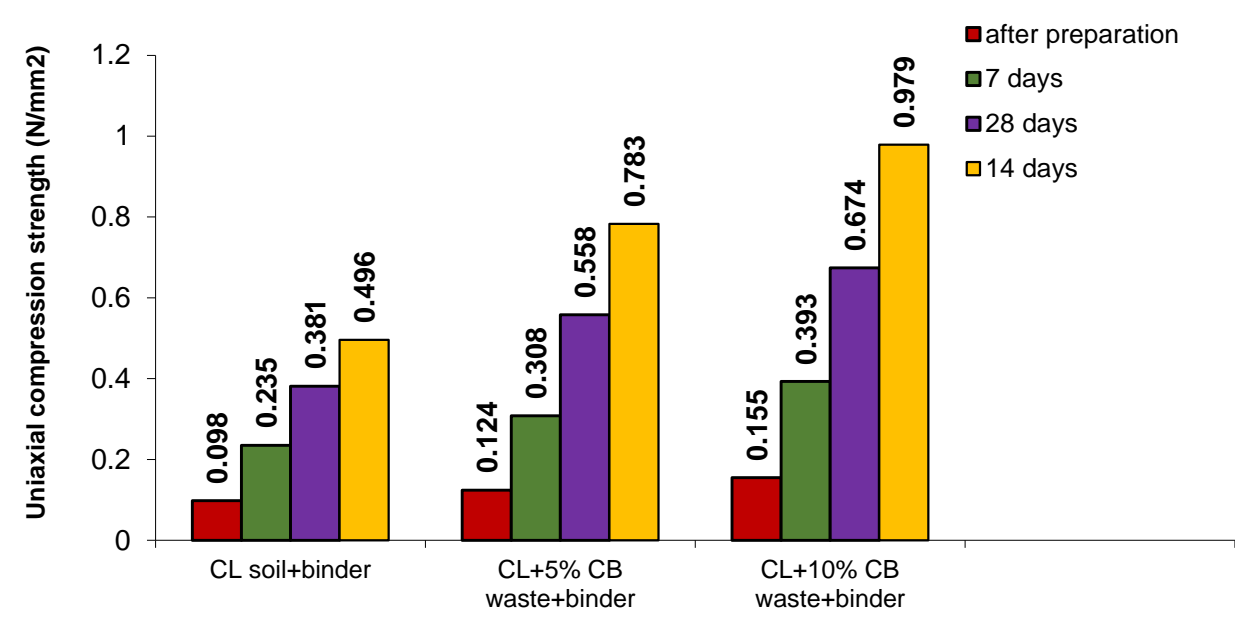

Fig. 1. Variability of compression strength values for the admixtures with concrete and brick waste.

Similar procedure has been applied for the second set of specimens with drywall waste and 5\% eco-binder with puzzolanic character, as illustrated in Fig. 2. 


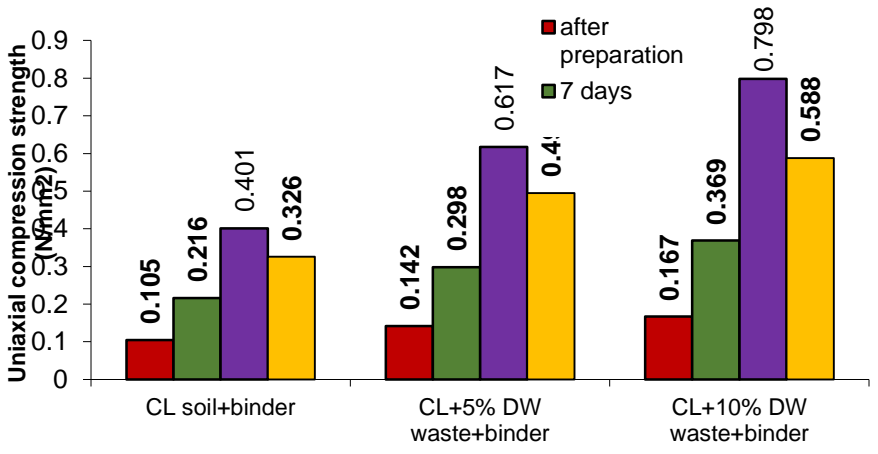

Fig. 2. Variability of compression strength values for the admixtures with drywall waste.

A different set of specimens to perform oedometric tests were prepared in order to assess the stabilizer effect of waste materials and water-based polymeric binder addition on the compressibility characteristics of mixtures. During the tests, the sample settlement at different loading stages allowed the calculation of oedometric modulus, coefficient of volumetric compressibility and compressibility coefficient $(a v)$ of prepared specimens. The determination of swelling pressure consists of the volume changes estimation caused by water content variations under complete inundated conditions and evolution records of the swelling at different time intervals. The compressibility indices are summarized in Table 1 .

Table 1. Compressibility parameters of admixtures.

\begin{tabular}{|c|c|c|c|c|c|}
\hline \multirow{2}{*}{$\begin{array}{c}\text { Compressibility } \\
\text { index }\end{array}$} & \multicolumn{5}{|c|}{ Admixtures } \\
\cline { 2 - 6 } & $\begin{array}{c}\text { Mix 1 } \\
\text { Reference } \\
\text { soil }\end{array}$ & $\begin{array}{c}\text { Mix 2 } \\
\text { 5oil + }\end{array}$ & $\begin{array}{c}\text { Mix 3 } \\
\text { Soil + } \\
10 \% \text { CB+binder }\end{array}$ & $\begin{array}{c}\text { Mix 4 } \\
5 \% \text { DW + binder }\end{array}$ & $\begin{array}{c}\text { Mix 5 } \\
10 \% \text { DW +binder }\end{array}$ \\
\hline $\begin{array}{c}\text { Oedometric } \\
\text { modulus } \\
\left(\begin{array}{c}\text { Eoed } 200-300, \\
\mathrm{kPa})\end{array}\right.\end{array}$ & 8220.15 & 12005.33 & 14478.87 & 10363.82 & 12623.15 \\
\hline $\begin{array}{c}\text { Coefficient of } \\
\text { volumetric } \\
\text { compressibility } \\
(m v, 1 / \mathrm{kPa})\end{array}$ & $1.36 \mathrm{E}-04$ & $9.34 \mathrm{E}-05$ & $7.02 \mathrm{E}-05$ & $9.76 \mathrm{E}-05$ & $7.45 \mathrm{E}-05$ \\
\hline $\begin{array}{c}\text { Compressibility } \\
\text { coefficient }(a v, \\
1 / \mathrm{kPa})\end{array}$ & $2.27 \mathrm{E}-04$ & $1.82 \mathrm{E}-04$ & $1.30 \mathrm{E}-04$ & $1.91 \mathrm{E}-04$ & $1.46 \mathrm{E}-04$ \\
\hline $\begin{array}{c}\text { Swelling } \\
\text { pressure }(\mathrm{kPa})\end{array}$ & 182 & 131 & 92 & 120 & 74 \\
\hline
\end{tabular}

\section{Results and discussion}

The compression strength values obtained for the admixtures with concrete and brick wastes, as well as drywall waste, were compared. For the tested specimens with concrete and brick materials and water-based polymeric suspension, after 7 days of curing, it can be 
observed an increase from $140 \%$ up to over $154 \%$ compared to the values obtained for the soil mixed only with stabilizer. A pronounced increase was observed after 14 and 28 days of curing, with major increases of about $289 \%$ up to $350 \%$, respectively $406 \%$ up to $532 \%$. Similar trend can be noticed for the specimens with drywall waste and powder eco-binder, where after 7 days of curing an increase from $106 \%$ up to over $121 \%$ compared to the values obtained for the soil mixed only with stabilizer was recorded. Also, a significant increase was observed after 14 and 28 days of curing, with major increases of about $210 \%$ up to $252 \%$, respectively $282 \%$ up to $378 \%$.

Comparing to other study focused on the assessment of the potential use of construction waste, such as brick or cement, on expansive soil [14], it can be noticed a similar increase of UCS values ranging from $0.4 \mathrm{~N} / \mathrm{mm}^{2}$ up to $0.6 \mathrm{~N} / \mathrm{mm}^{2}$ after 14 and 28 days of curing for the mixtures with the addition of $5 \%$ waste, and from $0.7 \mathrm{~N} / \mathrm{mm}^{2}$ up to $0.9 \mathrm{~N} / \mathrm{mm}^{2}$ for the mixtures with the addition of $10 \%$ of waste, similar to the results presented in the paper obtained for the mixtures after 14 days and 28 days of curing. Also, in terms of assessing the influence of waste addition on the swelling pressure, a similar trend of decreasing with increasing of waste quantity was indicated.

The analysis of compressibility indices revealed an increase of a maximum $76 \%$ of oedometric modulus for the admixtures with concrete and brick materials, respectively of about $53 \%$ for the ones with drywall waste. Moreover, regarding the variability of the swelling pressure, a decrease of about $49 \%$ for the first set of mixture, respectively $59 \%$ for the second one were observed, comparing to the values corresponding to the non-stabilized soil. By adding gradual percentage of construction waste a medium compressibility class for mixtures was achieved, but also the change of activity class of expansive soil by passing from the active category $(>100 \mathrm{kPa})$ to medium one $(50-100 \mathrm{kPa})$.

Likewise, based on the investigations carried out for improving the strength and consolidation properties of clayey soil using ceramic dust [15], a reduction of about $27 \%$ for both the compression and swelling index was obtained with the inclusion of construction wastes. It can be remarked that the higher decrease of the swelling pressure obtained in the present paper can be attributed to the addition of the water-based polymeric suspension in the prepared mixtures.

\section{Conclusions}

The present study emphasizes that a moderate addition of different construction waste can lead to a significant improvement of the strength and compressibility parameters. Both waste materials used in the admixtures were found to be effective in combination with a small quantity of stabilizer by following a specific technical procedure. On this basis, this kind of approach can be applied in order to reduce the demand of new resources for building sector, especially for road infrastructure works, and also to reduce the environmental impacts associated with the inappropriate disposal of the landfills.

The curing time was found to have a significant influence on the soil strength. It was concluded that the optimum stabilizing effect was most effective for the mixtures prepared with $10 \%$ concentration of waste and after 28 days curing time, but the most consistent increase appears at 14 days. In terms of compressibility, the addition of construction waste materials and binders revealed significant improvements rates, both on the oedometric modulus and swelling pressure.

The results of experimental tests demonstrate the benefits of waste reusing as byproducts, so called end-of-waste criteria by applying a non-standardized, but feasible technical method, as an efficient practice for preserving natural resources. 
The research and experimental application were made possible by financial support of Ministry of Research and Innovation in the framework of the National Research Programme "CRESC", PN 1610.04.02. Further studies are developed within the current research $24 \mathrm{~N} / 2019$ with focus on the use of industrial by-products in geotechnical engineering applications.

\section{References}

1. H. Yuan, A. R. Chini, Y. Lu, L. Shen, J. Waste Manage 32, 521-531 (2012)

2. M. Safiuddin, M. Z. Jumaat, M. Salam, M. Islam, R. Hashim, Int. J. Phys. Sci. 5, 19521963 (2010)

3. J. Bolden, T. Abu-Lebdeh, E. Fini, Am. J. Environ. Sci. 9, 14-24 (2013)

4. V. Tam, Recycling, Chapter 24 Recovery of Construction and Demolition Wastes (2014)

5. W. Lu, H. Yuan, J. Waste Manage 31, 1252-1260 (2011)

6. D. Xuan, L.J.M. Houben, A.A.A. Molenaar, Z. Shui, J. Wuhan Univ. Technol.-Mat. Sci. 25, 696-699 (2010)

7. A. K. Sabat, J. Geotech. Eng. 17, 3915-3926 (2012)

8. J. V. Puthussery, R. Kumar, A. Garg, J. Waste Manage 60, 270-276 (2017)

9. A. F. Cabalar, O. A. Zardikawi, M. D. Abdulnafaa, Road Mater. Pavement Des (2017)

10. R. Cardoso, R. V. Silva, J. Brito, R. Dhir, J. Waste Manage 49, 131-145 (2016)

11. C. S. Vieira, P. M. Pereira, Resour Conserv Recy 103, 192-204 (2015)

12. N. Cristelo, C. S. Vieira, M. L. Lopes, Procedia Eng. 143, 51-58 (2016)

13. C. F. Dobrescu, E. A. Calarasu, International Multidisciplinary Scientific GeoConference: SGEM, Bulgaria, Albena, 2, 495-502, (2016)

14. B J S Varaprasad, J.R. Joga, T. Rajesh, Y. Kumar, IJSTR 8, 3389-3393 (2019)

15. Md. A. Hossain, Md. Rashel Afride, N. H. Nayem, AJCE 7, 41-46 (2019) 